\title{
Representation of Farm Murders in Darrell Roodt's Treurgrond
}

By Dian Weys

Fall 2015 Issue of KINEMA

This article is available in Print edition of KINEMA

\section{Author Information}

Dian WEYS is a Masters student in Film Studies at the University of Cape Town. His main research interests include the ethics of spectatorship, apparatus theory and the spectacle, the influence of the media and consumer culture with specific focus on how the ubiquity of the media places a responsibility on the filmmaker. 